- To remove barriers to accessing hospice services.

Aims Empower palliative care patients to maximise their physical activity in order to promote an ongoing active lifestyle and develop resilience in managing the impact of their condition.

Method Paced Rehabilitation and Enablement Programme (PREP) is a community-based service at Willen Hospice funded by a grant from St James's Place Foundation and was developed in partnership with the local council and secondary care. PREP is an $8-12$ week programme delivered within a gym setting by a clinical team consisting of physiotherapy, occupational therapy, nursing and a gym instructor. The weekly two-hour programme includes exercise and education underpinned by an individual goal orientated ethos. The programme utilises a range of outcome measures to identify goals, progression and evaluate the overall impact of the service.

Results Of the eight patients who have so far completed the programme:

- all have achieved their goals

- all have improved their physical performance (Mean '3 metre timed up and go' increase of $5.8 \mathrm{~s}$; Mean 'sit to stands in 1 min' increase of 67\%)

- all are engaged in ongoing physical activity and participating in valued roles of their everyday life (country dancing, fishing and gym memberships)

- three patients want to return as volunteers to support other patients.

Conclusion We believe PREP is an ideal opportunity to empower palliative care patients to stay active for longer and to regain their sense of value and confidence and could be replicated across palliative care settings.

\section{P-149 EFFECTIVENESS OF PALLIATIVE CARE INTERVENTIONS OFFERING SOCIAL SUPPORT - A SYSTEMATIC REVIEW}

Natasha Bradley, Mari Lloyd-Williams, Chris Dowrick. University of Liverpool, Liverpool, UK

\subsection{6/bmjspcare-2017-hospice.174}

Background Social support is a necessary resource for good quality of life, particularly for individuals managing the psychological challenges of living with a life-limiting illness. Qualitative evidence describes social support obtained during palliative care interventions as valuable to the patient and beneficial to their wellbeing. Improving the quantitative evidence base is necessary to develop the application of economic evaluation in palliative care.

Aim(s) This systematic review aims to summarise existing quantitative evidence on the effectiveness (and cost-effectiveness) of interventions offering social support to individuals with life-limiting illness.

Method Research literature was identified through searching of electronic databases, reference picking and hand searches of key journals. Searches returned a total of 6247 unique titles of which sixteen were eligible for inclusion in this review.

Results Identified interventions included group therapies, group multidisciplinary interventions, and palliative day care. Outcome measures and study designs were heterogeneous. There was very limited use of economic evaluation. Statistically significant results were reported in areas including quality of life, mood disturbance, pain experience and symptom control. Benefits were frequently short term or influenced by participant characteristics (age, gender, baseline distress). Methodological limitations included attrition rates, insensitivity of outcome measures, and difficulties in capturing a true baseline.

Conclusions Although benefits in both psychological and physical domains were identified from palliative care interventions that include an element of social support, methodological problems and a scarcity of research has resulted in limited evidence of sustained benefit or cost-effectiveness. Existing evidence suggests that social support interventions may be more beneficial to some groups of patients than others.

\section{P-150 SOCIAL SUPPORT IN PALLIATIVE CARE}

Natasha Bradley, Mari Lloyd-Williams, Chris Dowrick. University of Liverpool, Liverpool, UK

\subsection{6/bmispcare-2017-hospice. 175}

Background A holistic approach to supporting a person with life-limiting illness and their families requires a consideration of their social context, including the availability of social support (defined as the resources gained from relationships with others). Hospices offer social environments, enabling opportunities to interact with others, maintain self-esteem and engage in group activities which are reported to be valuable opportunities to improve wellbeing. There has been limited research into the role of social support in palliative care, and whether the provision of such support has a measurable impact on patient outcomes.

Aims This three-year project will use mixed methods to explore services offered by hospices that facilitate social support, leading to a detailed understanding of social support in palliative care.

Methods A survey, disseminated to all hospices in the UK, will contribute knowledge on the establishment and variety of services that offer social support. Qualitative investigation including observations and interviews with service providers will seek to establish the meaning of social support in life-limiting illness and gain detailed understanding of services. A prospective study of patient reported outcome measures will be used to test the effectiveness (and if possible, cost-effectiveness) of these services.

Results An analysis of the results of the survey and preliminary qualitative findings will be presented.

Conclusions The project will contribute knowledge on the variety and significance of social support services in UK hospices and provide evidence for policy and decision makers on the necessity of social support in the context of life-limiting illness.

\section{P-151 HUMAN RIGHTS IN END OF LIFE CARE: DEVELOPMENT AND IMPLEMENTATION OF A PRACTITIONER'S GUIDE}

Jacqui Graves, Sue Hogston. Sue Ryder, London, UK

\subsection{6/bmjspcare-2017-hospice. 176}

Background There have been many reminders of losing sight of our humanity when delivering health care: the Mid-Staffordshire Enquiry (2013) and Winterbourne View (2012). The Care Quality Commission's new approach and the End of Life Care Education Framework for Scotland, are based on human rights principles. 
Mental Capacity and Safeguarding training is mandatory for most staff and yet human rights, which are the foundation for both, has been overlooked.

To meet this gap in practice, Sue Ryder worked with the British Institute of Human Rights to develop a Practitioners Guide. Following the learning from the demise of the Liverpool Care Pathway, a grant was secured from the Burdett Trust for Nursing to deliver a three year training programme. Aim To educate and empower the workforce to feel more confident in embracing human rights as an integral component to end of life care, by building on existing knowledge and experience, increasing awareness of how human rights can be used to aid decision making and ensure human rights values are at the heart of personalised care.

Methods Sue Ryder is delivering a three tiered training programme: half day workshops for the non-registered workforce; 1 day workshops for the registered workforce; two-day workshops for train the trainers to enable sustainability. Nottingham Centre for the Advancement of Research in End of Life Care will evaluate the training using a longitudinal mixed methods design, using pre and post training confidence questionnaires and interviews.

Results We have delivered four workshops and educated 49 practitioners to May. A further 26 workshops are planned. We project to have educated 444 practitioners, including 24 trainers, by the end of 2017. Qualitative feedback has been overwhelmingly positive.

Conclusion Everyone working in end of life care should understand their human rights responsibilities in order to deliver personalised care. The Sue Ryder training programme will increase practitioners understanding and confidence to fulfil their duty.

\section{P-152 THE LEGACY OF THE NOTHERN IRELAND CONFLICT IN PALLIATIVE CARE}

Brendan O'Hara. All Ireland Institute of Hospice and Palliative Care, Dublin, Ireland

\subsection{6/bmjspcare-2017-hospice.177}

Background Understanding the impact of the Northern Ireland 'Troubles'/'conflict' on a particular area of health care - palliative care - which has received little, if any, previous research focus. The research was carried out for a dissertation submitted in partial fulfilment for the degree of Master of Philosophy.

Aim(s) To investigate how the legacy of the Northern Ireland conflict may be encountered by professionals providing palliative care - to those they are caring for who may have been directly/indirectly affected (victims/survivors) and those involved in inflicting damage, death and/or injury. To investigate how the distinct context of Northern Ireland has impacted on palliative care practice.

Method Interviews were carried out with nine professionals with experience and interest in the provision of support to people with palliative care needs. Participants reflected experience across a wide geography of Northern Ireland including the region's two major cities, four of the region's five health and social care trust areas, and four of the five inpatient hospice facilities. Participants included: three nurses; two doctors; a social worker; a chaplain; a complementary therapist and a welfare officer.
Results This research opened up a dialogue between the disciplines of peacebuilding and palliative care. The language of legacy, narrative, life story and peacebuilding is one which the palliative care community understands.

The impact of the Troubles has had an effect on the delivery of palliative care, through the attitudes and influences on those who provide the care and those they care for.

Conclusion The influences of the religious divide, the silencing, and the traumas of the past are not something that the care-giver is apart from - they are very much influenced by them. The sensitivities around the Catholic/Protestant divide, the silencing, and restricting opportunities to talk about 'Troubles'-related trauma, could prevent people from having appropriate palliative care.

\section{P-153 STOPPING TRAFFIC}

Beth Ward. Demelza Hospice Care for Children, Sittingbourne, Kent, UK

10.1136/bmjspcare-2017-hospice. 178

The United Kingdom is one of the most prominent destination countries for people to be trafficked to in Europe. An estimated 20000 people are trafficked into (and throughout) the UK every year, with the majority of victims coming from, arguably, the poorest countries. This presentation outlines the case of a baby (aged two days) who was referred to a children's hospice for end of life care. Within the context of the direct work, it became apparent that the mother had been trafficked into the UK and had experienced periods of homelessness. The children's hospice social work team worked intensively to seek support for this mother, but due to high service demand, and the mother's questionable residency status, no statutory organisation was willing to engage. The NSPCC helpline recommended the Salvation Army, a Christian church and registered charity and this partner charity offered an assessment visit by their Anti-Human Trafficking Team's First Responder Co-ordinator and plans were subsequently put in place for the team to take on the supporting role after the baby's death. As well as focusing on safeguarding this extremely vulnerable family unit, it was essential that this mother had the opportunity to bond with her baby and to, albeit briefly, positively experience motherhood. The baby died peacefully, aged seven weeks. Pre-death planning had clarified the family's customs and rituals, which dictated that the parents did not attend the funeral and therefore, two members of the children's hospice team, together with two representatives from the Salvation Army were present, as a mark of respect. A year on, the mother continues to receive concerted support from the partnership charity, enabling her to preserve her dignity, reflect, recover and rebuild her life.

\section{P-154 THE VALUE OF SILENCE IN END-OF-LIFE SPIRITUAL CARE: CONNEXION, COMPANIONSHIP, POTENTIAL FOR CHANGE}

Lynn Bassett, Amanda F Bingley, Sarah G Brearley. Lancaster University, Lancaster, UK

\subsection{6/bmjspcare-2017-hospice. 179}

Background At the end of life silence seems to take increasing prominence in encounters between professional caregivers, patients and their family members but its value as an element 